\section{Merleau-Ponty e Marion: o problema da ambiguidade entre uma fenomenologia da percepção e uma fenomenologia da doação}

\author{
Ericson Falabretti ${ }^{1}$ \\ Professor de Filosofia da PUCPR
}

Resumo: As reflexões que encontramos na Fenomenologia da Percepscão, de Merleau-Ponty e em Étant Donné, de Jean-Luc Marion estão ancoradas, como manda a tradição fenomenológica, na redução. Para MerleauPonty, a redução fenomenológica se abre primordialmente para uma reflexão do irrefletido, da experiência perceptiva, a correlação mais original e espontânea entre os eventos mundanos e a atividade pré-pessoal do corpo próprio. Todavia, Merleau-Ponty, nos trabalhos dos anos $50 \mathrm{e}$, ainda no Visivel e o Invisivel, Merleau-Ponty julgará essa tentativa como uma má-ambiguidade, pois a percepção foi elevada a condição de um pensamento. Radicalizando a redução husserliana, a via de Marion - "A tanta redução, a tanta doação "abre-se para uma profunda discussão sobre a homologia fenomênica entre redução, doação e aparecimento. No ato de doação, o que se dá não é um fenômeno como evidência objetal, não é ente para o dasein ou, ainda, um fenômeno como síntese da nossa experiência pré-reflexiva, mas é dado como puro dom. A ambiguidade, portanto, constitutiva da doação, é uma espécie de acontecimento contíguo que radicalizaria todas as formas de redução fenomênica e não fenomênica ao colocar em cena um aparecer que se dá sem a proeminência de um objeto, de um sujeito ou, ainda, de qualquer forma de síntese intelectiva ou perceptiva. Em uma fenomenologia da doação, portanto, escaparíamos ao problema da má-ambiguidade, sempre presente em uma fenomenologia da percepção. Como? Eis o que eu busco entender.

Palavras-chave: ambiguidade, redução, percepção, doação, fenomenologia.

\author{
Merleau-Ponty and Marion: the \\ problem of an ambiguity between a \\ phenomenology of perception and a \\ phenomenology of donation
}

Abstract: The reflections that we find in the Merleau-Ponty's Phenomenology of Perception, and in the Étant Donné of Jean-Luc Marion are anchored, as required by the phenomenological tradition, in reduction. For Merleau-Ponty, the phenomenological reduction is primarily open for a reflection of the thoughtless, of the perceptual experience, the most original and spontaneous correlation between the mundane events and pre-personal activity of the body. However, Merleau-Ponty, in his works in the 50 s and even in The Visible and the Invisible, will judge this attempt as a bad ambiguity, since the perception was raised to the condition of a thought. Radicalizing Husserl's reduction, Marion's path - "So much reduced, so the donation" - opens into a deep discussion about the phenomenal homology between reduction, donation and appearance. In the act of donation, what happens is not a phenomenon as objectal evidence, is not being for dasein or even a phenomenon as a synthesis of our prereflective experience, but is given as pure gift. Ambiguity, thus, constitutive of the donation, it's kind of contiguous event that radicalize all forms of phenomenical and not phenomenical reduction by presenting the appearing that takes place without the prominency of an object, a subject, or even of any form of intellective or perceptive synthesis. In a phenomenology of donation, therefore, we would escape from the bad ambiguity's problem, always present in a phenomenology of perception. How? Here's what I seek to understand.

Keywords: ambiguity reduction, awareness, donation, phenomenology. 
Merleau-Ponty e Marion: o problema da ambiguidade entre uma fenomenologia da percepção e uma fenomenologia da doação

\section{Introdução.}

[...]o filósofo se reconbece por ter indistintamente o gosto da evidência e o sentido da ambiguidade. Quando ele se limita a submeter-se à ambiguidade, ela se chama equivoco. Para os filósofos maiores, ela se torna tema, contribuindo para fundar as certezas em vez de ameaçá-las. Seria preciso, portanto, distinguir uma má e uma boa ambiguidade". (M-P, 1986: 10)

Qual a relação entre uma fenomenologia da percepção e uma fenomenologia da doação? Para responder essa questão que envolve dois fenomenólogos da tradição francesa separados por quase meio século, não vou fazer uma discussão exaustiva sobre as obras de Merleau-Ponty e JeanLuc Marion. Como também não posso supor como Marion interpretaria diretamente a obra de Merleau-Ponty. Em Étant doné, a obra Merleau-Ponty, diferentemente dos trabalhos de Husserl, de Heidegger, Derrida e Lévinas ocupa um lugar periférico no livro de Marion. Merleau-Ponty é citado explicitamente apenas três vezes em Étant doné. Sempre na forma de rodapé, a $P H P^{2}$ ganhou uma transcrição direta sobre o fenômeno da doação e, ainda, uma referência sobre a multiplicação dos horizontes hermenêuticos a partir dos gêneros literários. Além disso, temos também a reprodução de uma bela passagem do $O E$ que parece corroborar a interpretação de Marion sobre a noção de efeito como a essência da invisibilidade de um quadro. Então, alguém poderia perguntar, porque recorrer a MerleauPonty para falar de Marion? Por que relacioná-los? Em Étant doné, sobretudo a partir do princípio "A tanta redução, a tanta doação", encontramos a possibilidade de uma nova re-leitura da volta ao irrefletido, à experiência perceptiva como foi proposta na $P H P$, sem os prejuízos de uma filosofia da consciência, daquilo que Merleau-Ponty nomeou como fórmula de uma má-ambiguidade presente na sua obra de 1945. Em uma das notas de 1959 do VI o tom crítico contra a PHP traz à luz a centralidade do problema deixado em aberto por essa obra canônica de 1945: "Os problemas colocados na PHP são insolúveis porque eu parto daí da distinção consciência - objeto -“ (M-P, 1999: 189).

Todavia, em que sentido a leitura de Marion pode nos ajudar a contornar o problema da má-ambiguidade? Ou, ainda, salvar Merleau-Ponty das suas próprias críticas? Étant doné não oferece uma resposta direta para esse problema, todavia, o que me parece mais razoável, é o fato de que o princípio "A tanta redução, a tanta doação," uma terceira via entre a objetividade husserliana e a etnicidade de Heidegger, escapa ao problema da máambiguidade ao reconhecer uma espécie de inseparabilidade fenomênica entre

2 Abreviaturas: PHP (Fenomenologia da Percepção); SC (Estrutura do Comportamento); VI (Visível e Invisível); $O E$ (O Olho e o Espírito), $M-P$ (Merleau-Ponty).

Revista de Filosofia Moderna e Contemporânea

Brasília, vol 3, no 2, 2015. 
aparecimento, doação e dom ' $^{3}$ "a coisa mesma pode definir-se enquanto aparece, porque aparece enquanto que se dá." (MARION, 200: 13). Isto é, será que em uma fenomenologia da doação o problema de um cogito constituinte tético - como fiador e fundante da experiência não estaria, finalmente, dissolvido? Em uma fenomenologia da doação, portanto, escaparíamos ao problema da má-ambiguidade, sempre presente em uma fenomenologia da percepção? Como? Eis o que eu busco entender.

\section{Redução e ambiguidade}

As reflexões da PHP e de Étant doné estão ancoradas, como manda a tradição fenomenológica, na redução. Merleau-Ponty, no belo prefácio da sua obra, nos diz que o tema da redução é o mais constante em Husserl. Já Marion praticamente reconstrói todas as etapas do pensamento husserliano, das elaborações de Heidegger até a sua própria obra pela démarche da redução. Discute o "surgimento em Husserl da redução como objetividade, retoma a virada da redução como etnicidade em Heidegger e, finalmente, propõe uma terceira via como caminho para radicalizar a redução pura ao dado enquanto tal.

As diferentes reelaborações de Husserl dessa temática revelam o seu esforço para conferir um estatuto filosófico aos fenômenos mundanos dados na consciência transcendental. A redução, ao reencontrar o cogito como ser-no-mundo, permitiu a Husserl a eliminação de toda forma de idealismo. Merleau-Ponty, atento às lições de Husserl, encontra na redução a união entre a concepção do ser e a existência do ser. Conforme Merleau-Ponty: "Longe de ser, como se acreditava, a fórmula de uma filosofia idealista, a redução fenomenológica é a fórmula de uma filosofia existencial." (MP, 1999: 11). Todavia, as diferentes retomadas husserlianas sobre a redução, da investigação do campo da experiência aberto pela redução fenomenológica transcendental até a crítica da experiência transcendental pela redução eidética, indicariam, nas palavras de Merleau-Ponty, "a impossibilidade de uma redução completa". Para Merleau-Ponty, de certo modo em consonância com o ponto de vista de Marion, na redução encontramos um "brotamento imotivado", experiências sem causas definidas, por isso mesmo, não seria possível explicitar uma consciência que constitui ativamente o sentido das experiências vividas, pois na redução rompemos com a familiaridade do mundo e com qualquer noção de espírito absoluto: "A reflexão não é absolutamente transparente para si mesma, ela é sempre dada para si mesma em uma experiência [...], ela sempre brota sem saber ela mesma de onde brota, e sempre se oferece a mim como um dom da natureza." (M-P, 1999: 74). Para Merleau-Ponty, a redução fenomenológica se abre primordialmente para uma reflexão do irrefletido, da experiência perceptiva - "um dom que a natureza oferece a mim" - que abarcaria a

\footnotetext{
${ }^{3}$ De modo geral, o sujeito para Marion é concebido como l'adonné, como alguém que se entrega a um dom que não comporta uma racionalização, isto é que não pode ser constituído por um sujeito, mas sobre o qual ele se acha sempre exposto. "O dom não consiste em um objeto transferido, senão sua donabilidade. Por donabilidade entendemos tanto uma determinação do dom dado como do doador... A donabilidade não permite somente desejar dar, senão que a solicita - o dom como aquilo que tem que ser dado. ( MARION, 2005: 154).
}

Revista de Filosofia Moderna e Contemporânea

Brasília, vol 3, no 2, 2015. 
Merleau-Ponty e Marion: o problema da ambiguidade entre uma fenomenologia da percepção e uma fenomenologia da doação

correlação mais original e espontânea entre os eventos mundanos e a atividade prépessoal do corpo próprio. Portanto, a percepção, esse brotamento imotivado aberto pela redução, uma doação da natureza - é o meu acesso primordial ao mundo, é o meu contato permanente com as coisas e com o outro: "Portanto, não é preciso perguntar se nos percebemos verdadeiramente um mundo, é preciso dizer, ao contrário, o mundo é aquilo que nos percebemos." (M-P, 1999: 14,). A tese central da percepção na PHP estabelece que percebo a partir da minha condição de ser-no-mundo e que tudo o que percebo se apresenta como uma estrutura de sentido dado em um contexto do tipo figura e fundo. Mas o que significa ser-no-mundo e perceber num contexto desse tipo?

A percepção não é uma operação anterior e nem posterior ao sentir, ela é contemporânea a todos modos de sentir. A percepção nunca se reduz a uma experiência fechada, pois toda a percepção apreende um sentido ou uma significação envolta em um campo de horizonte espacial e temporal que permanece aberto. $\mathrm{Na}$ percepção o determinado supõe o indeterminado, assim como o sentido arrasta consigo o não-sentido, o invisível se aloja na carne do visível e o presente carrega consigo todas outras vagas temporais:

[...] eu não penso na tarde que vai chegar e em sua sequência, e todavia ela "está ali", como o verso de uma casa da qual vejo a fachada, ou como o fundo sob a figura. Nosso porvir não é feito apenas de conjecturas e de divagações. Adiante daquilo que vejo e daquilo que percebo, sem dúvida não há mais nada de visivel, mas meu mundo continua por linhas intencionais que tracam antecipadamente pelo menos o estilo daquilo que virá (embora nós esperemos sempre, e sem dívida até a morte, ver aparecer outra coisa). O próprio presente (no sentido estrito) não é posto. O papel, minha caneta, eles estão ali para mim, mas en não os percebo explicitamente, eu antes conto com uma circunvizinhança do que percebo objetos, eu antes me dedico à minha tarefa do que estou diante dela. Husserl chama de protensões e retenções às intencionalidades que me ancoram em uma circunvizinhança. Elas não partem de um Eu central, mas de alguma maneira de meu próprio campo perceptivo, que arrasta atrás de si seu horizonte de retencões e por suas protensões morde o porvir." (M-P, 1999: 558)

Um exame da estrutura figura e fundo revela que a ambiguidade, nesse caso, não se refere a imperfeições, mas à possibilidade de uma percepção que nunca esgota o próprio percebido ou o ato de perceber. É a própria ambiguidade que passaria a ter um caráter positivo ao supor que a percepção não está nem no domínio do percepiente e nem do percebido. A percepção, por um lado, revela a figura e o fundo como, por outro lado, não permite distinguir absolutamente onde termina $\mathrm{O}$ fundo e começa a figura. A figura, ao mesmo tempo em que se destaca do fundo, permanece, na mesma situação, ligada a esse fundo que parece sustentá-la. $\mathrm{Na}$ relação figura e fundo o percebido está sempre no meio de outra coisa, ancorado em uma circunvizinhança, ele está dado em um campo no qual a fronteira entre o visto e o não visto permanece dinâmica $\mathrm{e}$ brota sem motivo específico, como uma dádiva da natureza.

Revista de Filosofia Moderna e Contemporânea

Brasília, vol 3, no 2, 2015. 
Todavia, o problema da má-ambiguidade, já está anunciado desde $S C$. A teoria das formas, na primeira obra de MerleauPonty, permitiu superar as perspectivas antitéticas sobre a relação entre consciência e natureza (intelectualismo e empirismo) e, por consequência, ultrapassar as explicações excludentes sobre o comportamento: o objetivismo científico das teorias de Pavlov e Watson e o introspectivismo psicológico:

\section{[...] o comportamento não é uma coisa mas também não é uma ideia, não é um invólucro de uma pura consciência e, como testemunha de um comportamento, não sou uma pura consciência. É justamente isso que queríamos dizer, dizendo que ele é uma forma. (M-P. 2006: 138)}

Todavia, o mais importante é considerar o sentido articulador que a teorias das formas adquire no processo de compreensão e descrição das relações entre os diferentes campos que operaram nas relações entre consciência e natureza. A teoria das formas integra o campo físico - sistema de forças mecânicas orientadas - o campo fisiológico - sistema de tensões e correntes - e, se considerarmos as formas simbólicas, $\mathrm{O}$ campo mental. Para Merleau-Ponty a teoria das formas articula as três ordens - a física, a vital e a humana - como três tipos de estruturas integradas. Em uma bolha de sabão como em um organismo, diz Merleau-Ponty (2006: 205), "o que se passa em cada ponto é determinado pelo que se passa em todos os outros". Desse modo, as acepções explicativas da ordem física, vital e humana consideradas, respectivamente, quantidade, ordem e significação são universalmente aplicáveis e intercambiáveis entre elas. A significação, por exemplo, ao mesmo tempo em que tem o seu valor objetivo no estudo da vida, tem seu lugar na compreensão dos sistemas físicos. Todavia, a separação entre consciência e natureza, entre a ordens física, vital e a ordem humana, é reinstalada por MerleauPonty quando ele concede primazia à ordem humana em relação as anteriores: "a ordem humana da consciência não aparece como uma terceira ordem sobreposta às outras duas, mas como sua condição de possibilidade e seu fundamento" (M-P, 2006: 139.) Merleau-Ponty, nesse caso, reabilitaria o idealismo transcendental kantiano, ao conceder ao cogito (constituinte) uma primazia transcendental sobre a matéria e a vida (a natureza constituída). Estamos, agora, no domínio da má-ambiguidade.

Este problema é, também, reintroduzido na PHP. A percepção é naturante e naturada, verdade e facticidade, comporta o noemático (objeto) e o noético (sujeito), é o verdadeiro fundamento da racionalidade. A percepção fornece sua estrutura ao pensamento, mas entre os dois opera uma relação de fundação cruzada - Fundierung ${ }^{4}$ - no qual os dados percebidos são retomados, usados, sublimados ao nível do pensamento por uma potência simbólica que os ultrapassa. Mas a Fundierung é sempre uma fundação na forma de uma constituição ambígua. Assim, por exemplo, a natureza funda a história e a cultura, como inversamente, porque estão assentadas em uma mesma base ontológica, a cultura e a

\footnotetext{
${ }^{4} \mathrm{Na}$ Fenomenologia da Percepção, o conceito de Fundierung, traduzido por fundação se refere a noção de estabelecimento. Nos anos 50, Merleau-Ponty abandonará o termo Fundierung e começara a utilizar e traduzir o termo Stiftung como instituição.
}

Revista de Filosofia Moderna e Contemporânea

Brasília, vol 3, no 2, 2015. 
Merleau-Ponty e Marion: o problema da ambiguidade entre uma fenomenologia da percepção e uma fenomenologia da doação

história fundam a natureza. O pensamento, por meio da sua liberdade, da sua potência criadora e expressiva, faz aparecer constitui - no domínio do simbólico o fundo pré-reflexivo da existência, nas palavras de Merleau-Ponty: "este dom da natureza que o Espírito precisava utilizar para além de toda esperança, ao qual ele devia dar um sentido radicalmente novo e do qual todavia ele tinha necessidade não apenas para se encarnar, mas ainda para ser." (M-P, 1999: 178). Desse modo, a percepção funda o pensamento, mas é por meio do pensamento que a percepção se manifesta, pois é sobre a base da percepção que esta potência pode constituir-se: "Assim como a natureza penetra até no centro de minha vida pessoal e entrelaça-se a ela, os comportamentos também descem na natureza e depositam-se nela sob a forma de um mundo cultural." (M-P, 1999: 465) Todavia, o equívoco dessa fundação cruzada, dirá Merleau-Ponty, é "insuperável, definitivo", pois, poderíamos dizer, toda a tentativa de pensar a percepção, de reabilitá-la no domínio do cogito, é um abandono da sua doação originária - do seu brotamento imotivado - no âmbito da sensibilidade. Nos trabalhos dos anos 50 e, ainda no $V I$, Merleau-Ponty julgará a Fundierung como uma má-ambiguidade, pois a tentativa de unir dois termos numa relação recíproca, naturante e naturado e de compreender o pensamento como uma percepção, elevou a percepção à condição de um pensamento. Em Parcoux, texto de 1951, Merleau-Ponty escreve: "O estudo da percepção somente podia nos ensinar 'uma má-ambiguidade', a mistura da finitude e da universalidade, da interioridade e da exterioridade." (M-P, p. 2000: 30). Portanto, o prejuízo da tradição que
Merleau-Ponty pretendia superar por um reconhecimento do primado da percepção, nasce e é alimentado pela própria tese da função fundante-constitutiva da percepção. Todavia, o último Merleau-Ponty, do inacabado $V I$, responde, de certo modo, aos problemas da $P H P$ - a tentativa de uma teoria da fundação cruzada - em direção à uma ontologia do ser bruto, no qual o sentido já está dado no tecido que formamos com o mundo. A reversibilidade, vivificada na experiência da mão que toca e é tocada, é estendida do corpo próprio para a carne do mundo, assim como a fé perceptiva - nossa crença inicial e cega que sustenta o nosso contato com o ser - nos dá a certeza da existência imotivada de algo que a nossa percepção não abarca completamente e não constituí, pois tudo aquilo que se dá no fundo não racional da nossa existência já é instituição de um sentido que se dá sempre como uma figura sobre um fundo inesgotável:

Mas existe, no fenômeno de expressão,
uma boa ambiguidade, isto é uma
espontaneidade que realiza aquilo que
parecia impossivel, a considerar os
elementos separados, que reúne em só
tecido a pluralidade das mônadas, o
passado e o presente, a natureza e a
cultura" (M-P,2000: 30).

Assim, ainda nos Resumos dos Cursos dos anos 50, já anunciando a virada ontológica do VI, Merleau-Ponty, de certo modo, antecipa a perspectiva de Marion ao estabelecer que o sentido do que é o dado, do que é criado não é constituído, já está instituído no seu próprio aparecer. $\mathrm{Na}$ filosofia, semelhante à análise de MerleauPonty sobre a pintura, cada obra, podemos

Revista de Filosofia Moderna e Contemporânea

Brasília, vol 3, no 2, 2015. 
concluir, anuncia as seguintes, e faz com que não possam ser semelhantes.

\section{Fenomenologia da doação}

Nas duas apresentações da edição Étant doné, francesa e espanhola, escritas em tempos diferentes, Marion insiste que essa obra é um momento dentro de um conjunto. Um leitor cuidadoso, por isso mesmo, deveria levar em conta as obras Réduction et donation; Recherches sur Husserl, Heidegger et la phénoménologie (1989) para interpretar a nova via fenomenológica aberta por Étant doné .

Radicalizando a redução husserliana, a via de Marion:

A tanta redução, a tanta doação "- abrese para uma profunda discussão sobre a homologia fenomênica entre redução, doação e aparecimento. Em Marion, diferente das perspectivas de Husserl, de Heidegger e de Merleau-Ponty, o sentido está dado no próprio aparecer sem qualquer referência a um doador ou, ainda, a uma operação de constituição do cogito, pois: "Admitir a fenomenicidade própria de um fenômeno seu direito e sua potência de mostrar-se a partir de si mesmo - implica compreendê-lo a partir da doação.(MARION, 2005: 35).

No ato de doação, o que se dá não é um fenômeno como evidência objetal, não é ente para o dasein ou, ainda, um fenômeno como síntese da nossa experiência préreflexiva, mas é dado como puro dom, reunindo o ato de doação, o doador e o donatário, estamos, agora, no campo da boa ambiguidade: “[...] Essa ambiguidade é imposta sem rodeios: doação significa de fato tanto o ato (dar) como aquilo que está em jogo (dom), incluindo o seu ator (doador) e o modo do dado já cumprido (natureza do que é dado) [...]" (MARION, 2005: 91). A ambiguidade, portanto, constitutiva da doação, é uma espécie de advento contíguo que radicalizaria todas as formas de redução fenomênica ao colocar em cena um aparecer que se dá sem a proeminência de um objeto, de um sujeito ou, ainda, de qualquer forma de síntese intelectiva ou perceptiva.

Em primeiro lugar, como diz Marion, não se trata apenas de explorar a ambiguidade, mas de reconhecer a polissemia que envolve o conceito de doação. Mas o que isso significa? A ambiguidade, como Marion sugere, está presente no próprio conceito de doação, tanto na matriz francesa como alemã do termo [Gegebenheit].

O exame da palavra doação, na língua francesa, põe em cena uma dualidade constitutiva do próprio termo: a doação persiste e oculta-se. Primeiro, a doação coloca em evidência o que já se acha dado, o próprio dom. Nesse caso, podemos inferir, a doação permanece - transparece - no dom dado. Todavia, a doação, também, desaparece no dado, ela é ocultada pelo dom dado. Pois a partir da doação temos a abertura de uma temporalidade, a inauguração de uma situação comandada, em grande parte, pelos dados doados. Para explicar melhor essa ambiguidade, Marion recorre a exemplos práticos: uma prova de matemática, um jogo de cartas, o dado genético e o dom artístico. Em um exame escolar, os dados que compõem um problema matemático não foram escolhidos pelo aluno, foram impostos por uma autoridade acadêmica. Os dados que compõem o problema surgiram a partir de

Revista de Filosofia Moderna e Contemporânea

Brasília, vol 3, no 2, 2015. 
Merleau-Ponty e Marion: o problema da ambiguidade entre uma fenomenologia da percepção e uma fenomenologia da doação

uma doação no qual boa parte deles eram ignorados e permaneciam indisponíveis até o momento da doação: a escolha das premissas para a montagem do problema; o desenvolvimento científico que deu origem ao problema etc. Mas assim que a prova é distribuída - dada - o dados se tornam acessíveis e um novo tempo recomeça para quem os recebe, o tempo da prova. Esses dados doados, imprescindíveis para fazer aparecer e resolver o problema, não remontam a um doador específico, a autoridade acadêmica, assim como não tem uma origem precisa. Assim todo dado, nos termos de Marion "la doné, la donnée, le datum", surge, revela-se e se identifica com a doação. Em um outro exemplo, do jogo de cartaz, essa lógica parece ainda mais clara. O início do jogo está condicionado a distribuição das cartaz e, nesse caso, pouco importa quem dá as cartaz. Mas tão logo as cartaz sejam distribuídas para o jogadores - doadas - o tempo do jogo se inicia mediante a uma conjuntura armada pela distribuição cega e imprevisível das cartaz, isto é, pela doação. Essa dualidade da doação, a sua persistência e o seu ocultamento no jogo, Marion explica como uma dobra do dado, pois se a doação, ambiguamente, permanece na origem do dom dado, ainda que não esclareça a sua genealogia, o dom dado se impõe como um acontecimento e um processo. : "Implementando-se, a doação articula o dom dado (eventualmente sem origem, nem genealogia, nem dependência, pouco importa) sobre seu processo de acontecimento..."'( MARION, 2005: 96). A dobra, nesse caso, explicita a ambiguidade da doação: um acontecimento sem causa definida que se desdobra a partir de um dado impessoal e contingente, pois a doação, ao mesmo tempo, que nasce do dado dele se desprende e permanece na abertura de um novo campo existencial, que tem origem na própria doação.

O sentido de doação, traduzido do alemão Gegebenheit - termo usado por Husserl que "abrange tanto o que é dado como o caráter de ser dado" - mostra, como estabelece Marion, que a "suposta ambiguidade da doação não anuncia mais do que o seu conceito : a dobra enquanto doação "(MARION, 2005: 100). É na matriz alemã do termo que a doação parece encontrar a sua significação mais rica.

Esta definição - que parece superar, definitivamente, as perdas de uma máambiguidade - leva a quatro pontos destacados por Marion como componentes essenciais fenomenicidade dos fenômenos como manifestação ou aparecimento do que é dado. Em resumo: 1) Tendo em conta as elaborações husserlianas, sobretudo em A Ideia de Fenomenologia, "sobre a correlação entre o aparecer [Erscheinen] e o aparecente [Erscheinenden]", Marion estabelece que a dobra da doação incorpora - estrutura - o dado como doação e, por sua vez, a própria doação como surgimento do que é dado, colocando em evidência a correlação entre a doação absoluta [absolute Gegebenheiten]; a doação do aparecer [Gegebenheit Erscheinens] e a doação do objeto [Gegebenheit des Gestandes]; 2) $\mathrm{O}$ fenômeno aparece tal com é, sem nenhum déficit, assim o aparecer não se submete a nenhum fundamento ou condição exterior à própria aparição ; 3) "Dar-se equivale a mostrar-se, o que se mostra se dá (MARION, 2005: 101 ); 4) O fenômeno não aparece porque seria um ente (Heidegger) ou um objeto (Husserl), como não aparece a partir e de desde de si

Revista de Filosofia Moderna e Contemporânea

Brasília, vol 3, no 2, 2015. 
mesmo sem a doação, o fenômeno somente aparece - dá-se desde de si mesmo - sob a autoridade de uma doação. A doação estaria na origem do aparecer.

A doação como implementação de uma dobra diante do dado, nos permite pensar sobre o sentido último de uma boa ambiguidade, pois a doação enquanto dobra põe em cena um fenômeno que só pode aparecer enquanto tal e enquanto é doado como um dom. Portanto, a doação, como na experiência do pintor no qual o mundo se oferece, é mas uma dobra que se faz e se desfaz a partir de um dado e que só aparece na medida em que é doado. Todavia, para entender melhor a fenomenalidade como doação é preciso destacar quatros características fundamentais de todo fenômeno dado que parecem afastar a fenomenologia da doação dos prejuízos de uma má-ambiguidade, nascida do conceito de fundação cruzada - fundierung -, como já discutimos.

A primeira é a anamorfose. Trata-se de uma técnica, um efeito de pintura que exige do espectador um olhar dirigido a um ponto específico da tela como condição a partir do qual o quadro poderá ser visto. $\mathrm{O}$ fenômeno dado, semelhante a um quadro realizado no jogo perspectivo da anamorfose, se manifesta desde si com a sua forma própria, o fenômeno dado se impõe ao sujeito como a forma de um quadro invade o nosso olhar contemplativo. Em O Enigma de William Tell (1933), por exemplo, Salvador Dali empregou uma jogo perspectivo sobre as figuras e o plano do quadro, alongando-as e distorcendo-as, exigindo do espectador um ponto de vista oblíquo. $O$ sujeito não constitui o fenômeno dado, ele deve recebê-lo como se contempla um quadro, assumido o ponto de vista da obra, aceitando o modo como ela se oferece, o único pelo qual ela pode ser vista.

Se a anamorfose estabelece que o fenômeno se dá a partir de si, "l'arrivage" nos diz que a significação de todo fenômeno dado irrompe na temporalidade. Isso não significa que o fenômeno dado é um acidente, mas que o sujeito é "impotente" para fazer um fenômeno aparecer, pois todo fenômeno dado é contingente e encontra o seu sentido no tempo. Para Marion, em uma interpretação distinta da tese husserliana de que na redução fenomenológica reencontraríamos a idealidade atemporal do fenômeno, o seu eidos, é preciso considerar uma contingência original do dado sem nenhuma antecipação possível do fenômeno. $\mathrm{O}$ fenômeno dado antecede o próprio movimento de intencionalidade, Mesmo a ideia de intencionalidade - de fluxo de ek-stase da consciência - não é mais o modo privilegiado de temporalização. Não se trata, escreve Marion, de negar a intencionalidade e as atividades de síntese ou de constituição, mas é preciso aceitar que elas somente são possíveis depois da doação, conforme atestam as análises sobre a anamorfose e l'arrivage: "Assim se estabelece um dos caracteres do dom reduzido: a doação, a propriedade intrínseca de dar-se desde si mesmo e somente a partir de si" (MARION, 2005: 227). Todavia, l'arrivage não se limita a ser apenas um acontecimento inesperado, a contingência fenomenológica intrínseca também nos conduz a sua admissibilidade, "a sua característica de poder, desde si mesmo, fazer aceitar-se" (MARION, 2005: 228). Além do mais, a partir do conceito de l'arrivage, a contingência temporal, pensada fenomenologicamente, é, em última instância, o que o individualiza o fenômeno, "o radica em um momento

Revista de Filosofia Moderna e Contemporânea

Brasília, vol 3, no 2, 2015. 
Merleau-Ponty e Marion: o problema da ambiguidade entre uma fenomenologia da percepção e uma fenomenologia da doação

único” (MARION, 2005: 255). A temporalização do fenômeno dado e sua admissibilidade brotam da doação.

As outras duas características do fenômeno dado, "le fait accomplice" e "o incidente", reforçam a tese de que não há substância prévia e nem conceito a priori anterior à doação. Marion, desse modo, aprofunda as consequências das ideias de contingência e admissibilidade. "Le fait accomplice" antes de tudo, reabilita e estende, no interior de uma fenomenologia da doação o conceito de facticidade. Marion, antes de tudo, não aceita a tese heideggeriana de que a facticidade seria uma condição própria do Dasein. Para Marion é preciso considerar que os fenômenos estão presentes no mundo como fatos [factum]: "O surgimento do fenômeno dado (contingente) encontraria aqui o seu sentido na facticidade de um fato [factum], que se daria, então, aparecendo sob o modo da facticidade" (MARION, 2005: 242) Mas é preciso considerar as consequências desse vínculo essencial no fenômeno dado, entre l'arrivage e a facticidade para fenomenologia. Primeiro não há necessidade prévia de saber se o fato - o fenômeno do mundo é eterno, mas tão somente que ele aparece, que ele se dá. Depois, é o próprio conceito de causa - núcleo do pensamento metafísico - que parece perder importância. A admissibilidade da facticidade do fenômeno dado e a sua contingência parecem libertá-lo do exame das causas, pois esse exame só é possível a posteriori. Tudo deve começar pelo fato, pela persistência da doação, pois o passado - a reconstrução causal - assim como o futuro - a previsibilidade - perdem lugar para a tese de que "le fait accomplice", ambiguamente, está destinado a permanecer para sempre e/ou acabar-se, mas, desde o momento que ele se mostra, ele dá sem reservas. Tomando como exemplo o fenômeno da Revelação, tal como foi descrito por Schelling em $A$ Filosofia da Mitologia, Marion resumo em três pontos essa determinação da facticidade que, mais a frente, ele chamará de ampliada em relação as elaborações de Schelling, de Husserl e Heidegger:

I) sobre um fato "não podemos afirmar nada antes de reconhecer que ele teve lugar, que foi produzido, que aparecen de fato; II) esse fato é, cada vez, absolutamente primeiro, originário (sem causa) e sem precedente (individualizado) [...] de modo que ele pode inangurar aquilo que pode se temporalizar na história [...]; III) $O$ fenômeno dado me acontece pois de fato, isto é, a titulo de fato originário, por excelência e irrevogável. (MARION, 2005: 242)

Ao sustentar o ponto de visto que um fenômeno dado, reencontrado no domínio da facticidade, é um fato consumado, Marion coloca em questão os fundamentos da metafísica clássica e da ciência moderna. Em uma fenomenologia da doação, noções como substância, causalidade e previsibilidade, perdem a centralidade para uma concepção marginal e teoricamente nula no interior do discurso metafísico e do pensamento objetivo, a noção de incidente/acidente, a quarta determinação de um fenômeno dado. Desde Aristóteles, interpreta Marion, $\mathrm{o}$ incidente sempre foi pensando sobre o domínio da privação e da imprevisibilidade causal. Encontrar por pura fortuna um tesouro ao cavar desavisadamente um jardim ou, ainda, chegar de barco a uma ilha por eventos imprevistos como pela força da marés, conforme relata Aristóteles

Revista de Filosofia Moderna e Contemporânea

Brasília, vol 3, no 2, 2015. 
em A Metafísica, são fenômenos que pertencem ao inteiramente ao campo da contingência, de uma causalidade imprevista, de um acontecimento extra que se opõe a ousía. A metafísica aristotélica, como interpreta Ross (1987: 170), toma o ser por acidente como um "acessório", como algo que "não pode ser estudado" em função do seu número "infinito de atributos". Todavia, estabelece Marion, a ousía pode coincidir com o incidente. Em Santo Tomás de Aquino, na leitura de Marion, a criação é um acidente da natureza, vem do exterior como incidente no qual a essência não coincide com o ser, pois somente em Deus a essência e ser podem coincidir. A criação, analisa Marion, pode ser concebida sem ser, isto é como um incidente fora da essência, um acontecimento extra. Assim, o ser mesmo, a exceção de Deus, e o fato dado, acontecem segundo a lógica do incidente: um ser sem ousia e sem explicação ou razão prévia. Mas, um incidente que se apresenta como um fato consumado, admissível a partir do seu próprio aparecer.

A anamorfose revela a presença e a significação do dom dado fora do jogo de correlação constituinte sujeito-objeto, pois o dom dado é, desde si mesmo, impregnado de sentido. L'arrivage, inaugura uma temporalização que não é mais pensada como uma categoria a priori da razão, o dom dado é um acontecimento que se impõe, que é admissível a partir do seu próprio aparecer. Já as noções de "le fait accomplice" e incidente nos mostram o caráter positivo da contingência na doação, afinal, todo fenômeno dado é, ao mesmo tempo, um fato consumado que advém na forma de incidente:

O fenômeno, enquanto dado, ascende desde si mesmo ao visivel segundo a anamorfose, se individualiza em sua chegada, se impõe irrevogavelmente por seu fato consumado e rechaça a completa construção, surgindo como um puro incidente. (MARION, 2005: 270)

\section{O fenômeno saturado.}

Para explorar melhor a noção de boa ambiguidade, vou me deter no fenômeno saturado de intuição que transborda os limites da fronteira do fenômeno pobre de intuição submetido às condições a priori da experiência possível. Temos, na verdade, uma tensão entre a doação do fenômeno saturado e a descrição formal do fenômeno reduzido às categorias do entendimento e da razão, como podemos ler em Kant. Nos reencontramos, a título de exemplo, o fenômeno pobre de intuição na ciência, em toda história da metafísica e no próprio Husserl. O fenômeno pobre aparece, sobretudo, na atitude de sobrevoo, no pensamento operatório que Merleau-Ponty contrapõe em $\mathrm{OE}$ a imersão corporal do pintor na "história primordial", no "sentido bruto", no visível que é dado e não requer nenhuma tese, nenhum conceito: "Ele (Cézanne) está ali, forte ou fraco na vida, mas incontestavelmente soberano em sua ruminação do mundo, sem outra técnica senão a que seus olhos e suas mãos oferecem à força de ver, à força de pintar [...]" (M-P, 2004: 15). Em Kant, o fenômeno pobre resulta da sua dependência das categorias do entendimento, da sua obrigação em converter-se sempre em uma tese. $\mathrm{Na}$ filosofia kantiana todo fenômeno - aquilo que aparece - somente pode aparecer segundo as condições formais e a priori da experiência (intuição e conceito). $\mathrm{Na}$ metafísica tradicional, o fenômeno pobre, também manifestaria

Revista de Filosofia Moderna e Contemporânea

Brasília, vol 3, no 2, 2015. 
Merleau-Ponty e Marion: o problema da ambiguidade entre uma fenomenologia da percepção e uma fenomenologia da doação

uma má-ambiguidade essencial entre o aparecer e o que aparece, pois ele sempre se constitui sob a judicação do princípio de razão suficiente. Em Husserl, o fenômeno pobre de intuição, seguindo Marion, operaria como princípio de intuição suficiente, pois no lugar do princípio de razão suficiente, para Husserl a intuição bastaria ao fenômeno, já que toda intuição doadora é uma fonte de direito para o conhecimento. No entanto, a intuição em correlato com a aparição não se justifica por si mesma, mas somente enquanto fornece dados originários. Desse modo, comenta Marion, todo fenômeno se legitima e aparece a partir de seus limites, já que toda intuição se dá num horizonte de vivências visadas e não visadas. Por isso mesmo, Husserl redefine o fenômeno a partir de um jogo de dualidade articulado a partir de um quadro de categorias complementares: intenção/intuição, significação/ preenchimento, noese/noema etc. Em Husserl, a evidência entre o aparecer e o que aparece (noese/noema) se realiza subjetivamente, isto é, o aparecer subjetivo equivale ao aparecer objetivo. Estamos, novamente, no domínio de um máambiguidade.

Já o fenômeno saturado, que também reencontramos na própria tradição metafísica e fenomenológica (o infinito em Descartes, o sublime em Kant, a consciência íntima do tempo em Husserl, como bem descreve Marion) transborda os limites das categorias do entendimento, revela um excesso de doação que suplanta toda atitude reflexiva. Se um fenômeno pobre de intuição, sujeito às categorias do entendimento, pode ser quantificável e representado pela linguagem formal da matemática, o fenômeno saturado, por sua vez, é imprevisível, insuportável, desmedido e inobservável. O fenômeno saturado, mostra-se, aparece, dá-se, antes de ser objetividade. A sua significação transbordante permanecerá sempre aberta. Os fenômenos saturados, pensados na contra-luz das categorias kantianas do entendimento, dãose como imprevisíveis (conforme a quantidade), insuportável (em relação a qualidade), absoluto (conforme a relação) e inobservável (segundo a modalidade). Em um fenômeno saturado não há síntese progressiva, mas imediata, não há horizonte, mas presença transbordante e, definitivamente, o eu transcendental não opera mais como doador de sentido. Tratase de um transbordamento doado, evidente, mas não explanável segundo as regras da razão. $O$ conceito não abarca a intenção, ao contrário, a doação satura o conceito, torna-o, ambiguamente, dado e invisível, presente e incomensurável, certo e incompreensível, não por falta, mas por excesso ou transbordamento de doação. Estamos, agora, no domínio, de uma boaambiguidade.

Em Descartes, por exemplo, a ideia de infinito aparece de uma só vez e é incomparável, não há analogia possível com o finito, e o Eu, transbordado por essa ideia, se rende a uma evidência clara e distinta, compreende parcialmente, mas não comporta o infinito: “ $[\ldots]$ pois é da natureza do infinito que minha natureza, que é finita e limitada, não possa compreendê-lo" (DESCARTES,1991:. 190).

Como exemplos paradigmáticos do fenômeno saturado encontramos na obra de Marion a história, um fenômeno que satura a categoria de quantidade; o ídolo

Revista de Filosofia Moderna e Contemporânea

Brasília, vol 3, no 2, 2015. 
que satura a categoria de qualidade; o ícone que ultrapassa a categoria do observável; a carne que subverte a categoria de relação pela auto-afecção. Todavia, é justamente no exame do fenômeno do ícone que as obras de Marion e Merleau-Ponty parecem superar definitivamente a má-ambiguidade.

No ícone o invisível emerge e, ao mesmo tempo, transborda do visível, se dobra e desdobra, como a carne do mundo. Essa ambiguidade do ícone, imagem visível que irradia o seu invisível, parece aproximar as análises de Marion e Merleau-Ponty, com bem estabeleceu Jenny Slatman em seu belo artigo Phenomenology of the Icon.

As análises da pintura, descritas em $O E$, reabilitam o conceito de imagem e o poder dos ícones contra a noção da imagem como cópia, do desenho como decalque e, contra a perspectiva cartesiana, da pintura como uma modalidade plana de representação de objetos extensos. MerleauPonty encontra na arte - mais especificamente na pintura - uma descrição do mundo sem o abandono da nossa experiência originária. A pintura, essa meditação profunda e silenciosa sobre a potência da visão, realiza uma figuração icônica do sentido bruto das coisas que parece impossível para a filosofia, mesmo para uma onto-fenomenologia. Desse modo, na experiência da pintura, reencontramos $\mathrm{O}$ poder do ícone para além da estrutura gramatical da linguagem. Pois um quadro, no conjunto formado pela cor, linha, textura, desenho e profundidade, como já apontava Klee, tem o mágico poder de expressar a nossa iniciação ao mundo, de desfazer todos os enigmas da visão, pois satura o visível em direção ao invisível: " $\mathrm{Eu}$ teria muita dificuldade de dizer onde está o quadro que olho. Pois não o olho como se olha uma coisa, não o fixo em seu lugar, meu olhar vagueia nele como nos nimbos do Ser, vejo segundo ele ou com ele mais do que vejo." (M-P, 2004:18). Não encontramos no quadros de Cézanne, na montanha de Santa Vitória uma cópia ou, ainda, o instante congelado de uma experiência visual da montanha, encontramos muito mais do que isso. Assim como no autorretrato de Cézanne, não vemos apenas a figuração do rabugento Cézanne, mas o índice invisível da familiaridade do nosso corpo com o mundo, do movimento da vida que se esvai no tempo como a noite que engole a tarde, da ligação íntima da cultura com a natureza. O rabugento Cézanne está lá, sem dúvida nenhuma, mas no autorretrato também vemos com ele e além dele, como indicam as belas palavras de Rilke sobre essa obra de Cézanne:

E como é grande e inabalável esta objetividade do seu contemplar! É o que se confirma de uma maneira quase comovente pela situação, por ele ter reproduzido a si mesmo sem mesmo a mais remota tentativa de interpretar sua expressão, sem vê-la presuncosamente, e com tão bumilde objetividade, com a fé e a participação interessada e objetiva de um cachorro, que se vê no espelho e pensa: aí está outro cachorro."(RILKE, 2006: 88)

Marion é um dos poucos pensadores a ter desenvolvido uma fenomenologia do ícone que parece levar a última potência a fórmula merleau-pontyna sobre o ícone: "vejo segundo ele ou com ele mais do que vejo." Em seu L'idole et la distance, Marion combate a idolatria metafísica da ontoteologia - que, eventualmente, se encaminha para um ateísmo - através da elaboração de uma filosofia da distância que desemboca em uma verdadeira

Revista de Filosofia Moderna e Contemporânea

Brasília, vol 3, no 2, 2015. 
Merleau-Ponty e Marion: o problema da ambiguidade entre uma fenomenologia da percepção e uma fenomenologia da doação

filosofia do divino. Pois a distância que é constitutiva do "contato" com o Deus se manifesta no ícone. O ícone, de acordo com Marion, não é a figuração de um Deus, mas "a visibilidade do invisível, onde a visibilidade do invisível aparece como tal." A proximidade com Merleau-Ponty, podemos dizer, é visível. Em La Croisée du Visible, como bem aponta Jenny Slatman, Marion nos mostra que o ícone é uma experiência contínua de troca de olhares. Assim, o ícone nos dá o invisível que é imprevisível. O ícone, nas palavras Slatman, "figura um vazio, um buraco, uma negatividade, uma privação: uma kenosis. Como Kenosis o ícone se esvazia de si mesmo, sem perder a própria identidade, para se fazer abertura ao outro e se encontrar no outro." (SLATMAN, 2009: 201). A kenosis ${ }^{5}$ se manifesta na troca de olhares, não se esgota, sempre aberta, transborda o visível, satura o previsível como a reversibilidade em Merleau-Ponty entre o vidente e o visível satura o sujeito transcendental. Como interpreta Jenny Slatman, enquanto Marion procura superar a "tirania enlameado do visível", ou voyeurismo idólatra por meio do efeito de oração que purifica os olhos, MerleauPonty opõe a pintura "ao pensamento operatório." Tanto para Merleau-Ponty como para Marion, portanto, o ícone é uma imagem que transcende o visível, que satura a cultura idólatra da visão, uma imagem que reencontramos na arte da pintura. Assim é preciso considerar a diferença que marca a distância entre $\mathrm{O}$ ídolo e o ícone. Enquanto o ídolo, como aparece em Deus sem o Ser, é uma representação de Deus, pois Deus será o que a instituição dos conceitos que atribuímos e imaginamos sobre Ele, o ícone, por outro lado, deixa Deus ser Deus, não é um objeto, não é um conceito, nem algo que temos à mão, é pura doação. Um quadro, como escreve Marion em $O$ Visivel Revelado,
se distingue de outros objetos visiveis precisamente naquilo que nenbuma significação pode farế-lo compreender, nem nos dispensa de reencontrar sua intuição [...] Um quadro, é preciso ir vế-lo, portanto revê-lo; não é preciso senão vê-lo, sem nenhuma outra intuição excepcional do que aquela do simplesmente ver, mas verdadeiramente." (MARION, 2010: 151).

Ver verdadeiramente um quadro, é, então, a experiência profunda da doação, é a vivência de um olhar que transborda a figura e transcende os limites do visível porque está orientado em direção a um ponto de fuga, para aquilo que está, ambiguamente, presente na ausência.

5 O vocábulo KENOSIS, dizem alguns eruditos, é oriundo do verbo grego, kenoun, que significa “esvaziar". No cristianismo essa noção encontra o seu sentido mais evidente a partir da citação de Paulo: "Seja a atitude de vocês a mesma de Cristo Jesus, que, embora sendo Deus, não considerou que o ser igual a Deus era algo a que devia apegar-se; mas esvaziou-se a si mesmo, vindo a ser servo, tornando-se semelhante aos homens" (Fp 2.5-7/ NVI).

Revista de Filosofia Moderna e Contemporânea

Brasília, vol 3, no 2, 2015. 


\section{Conclusão}

A filosofia de Merleau-Ponty é uma tentativa contínua de subverter a hegemonia do pensamento operatório circunscrito aos fenômenos pobres, para usarmos o léxico de Marion. Assim, na EC, Merleau-Ponty opõe à teoria do reflexo o comportamento absolutamente inapreensível e aberto da nossa experiência simbólica no mundo. $\mathrm{Na}$ PHP, o corpo objetivo é saturado pela noção de corpo próprio, um ente inobservável e inapreensível em toda sua medida, pois enquanto sentiente-sentido é um objeto que não me deixa e sobre o qual exerço apenas um poder parcial. Já no VI é a fé perceptiva, essa fé animal que existe antes de qualquer intenção e de qualquer tomada de posição que vem suplantar a penúria de uma percepção ainda presa à ambiguidade do pensamento de ver, enquanto a carne - deiscência inesgotável - me recoloca no âmago do ser.

Todavia, é preciso reconhecer que na passagem de uma filosofia da percepção para uma fenomenologia da doação, reencontramos o dado liberto dos limites da objetividade (Husserl) e da etnicidade (Heidegger), um fenômeno que escapa à má-ambiguidade, pois o dado aparece a partir de si, na medida em que se dá em e desde de si mesmo, ou ainda, deixando a si.

\section{Referências bibliográficas}

DESCARTES, René. Discurso do Método; As paixões da alma; Meditações Metafísicas; Objeções e Respostas. 5 ed. In: Os Pensadores. São Paulo: Nova Cultural, 1991.

MARION, Jean-Luc. Étant donné. Essai dune phénoménologie de la donation. Paris: PUF, Épiméthée, 2005.

O Visivel Revelado. (Tradução: Joaquim Pereira)São Paulo: Estação Loyola, 2010.

Grasset, 1977.

$$
\text { L'idole et la distance. Paris: }
$$

.Dieu sans l'être. Paris: PUF, 1991.

1991.

MERLEAU-PONTY. Oeuvres. Éditions. Gallimard, Paris, 2010.

Elogio da Filosofia. Lisboa: Guimarães editora. 1986.

Parcours Deux (1951-1961). Paris:

Éditions Verdier, 2000.

O Olho e o Espirito. São Paulo:

Cosac \& Naify, 2004.

Estrutura do Comportamento. São

Paulo: Martins Fontes, 2006.

Fenomenologia da Percep̧cão. São

Paulo: Martins Fontes, 1999.

. O Visível e o Invisivel. São Paulo:

Perspectiva, 1999.

Revista de Filosofia Moderna e Contemporânea

Brasília, vol 3, no 2, 2015.

101 
Merleau-Ponty e Marion: o problema da ambiguidade entre uma fenomenologia da percepção e uma fenomenologia da doação

ROOS, David. Aristóteles. Lisboa: Dom Quixote, 1978.

SLATMAN, Jenny. Merleau-Ponty and the possibilities of philosophy: transforming the tradition. Edited by Robert Vallier, Wayne Froman, and Bernard Flynn. Published by State University of New York Press, Albany, 2009

Revista de Filosofia Moderna e Contemporânea

Brasília, vol 3, no 2, 2015. 